\title{
The Role of Executive Function and Social-emotional Skills in the Development of Literacy and Numeracy during Preschool: A Cross-Lagged Longitudinal Study
}

\author{
Sharon Wolf \\ University of Pennsylvania,wolfs@upenn.edu \\ Dana Charles McCoy \\ Harvard University
}

Follow this and additional works at: https://repository.upenn.edu/gse_pubs

Part of the Developmental Psychology Commons, and the Early Childhood Education Commons

\section{Recommended Citation}

Wolf, S., \& McCoy, D. C. (2019). The Role of Executive Function and Social-emotional Skills in the Development of Literacy and Numeracy during Preschool: A Cross-Lagged Longitudinal Study. Developmental Science, 22 (4), E12800-. http://dx.doi.org/10.1111/desc.12800 


\title{
The Role of Executive Function and Social-emotional Skills in the Development of Literacy and Numeracy during Preschool: A Cross-Lagged Longitudinal Study
}

\author{
Abstract \\ The majority of evidence on the interplay between academic and non-academic skills comes from high- \\ income countries. The aim of this study was to examine the bidirectional associations between Ghanaian \\ children's executive function, social-emotional, literacy, and numeracy skills longitudinally. Children ( $N=$ \\ 3,$862 ; M$ age $=5.2$ years at time 1 ) were assessed using direct assessment at three time points over the \\ course of two school years. Controlling for earlier levels of the same skill, early executive function \\ predicted higher subsequent literacy and numeracy skills, and early literacy and numeracy skills predicted \\ higher subsequent executive function, indicating that the development of executive function and \\ academic skills is inter-related and complementary over time. Early literacy and numeracy predicted \\ subsequent social-emotional skills, but early social-emotional skills did not predict subsequent literacy \\ and numeracy skills. The findings provide longitudinal evidence on children's learning and development in \\ West Africa and contribute to a global understanding of the relations between various developmental \\ skills over time.

\section{Keywords} \\ cross-lagged panel analysis, early academic skills, executive function, Ghana, social-emotional, \\ sub-Saharan Africa

\section{Disciplines} \\ Developmental Psychology | Early Childhood Education | Education
}


Running Head: ACADEMIC \& NON-ACADEMIC SKILL DEVELOPMENT OVER TIME IN GHANA

The Role of Executive Function and Social-emotional Skills in the Development of Literacy and Numeracy during Preschool: A Cross-Lagged Longitudinal Study

\author{
Sharon Wolf \\ Graduate School of Education \\ University of Pennsylvania \\ 3700 Walnut Street \\ Philadelphia, PA 19103 \\ wolfs@upenn.edu \\ Dana Charles McCoy \\ Graduate School of Education \\ Harvard University \\ 14 Appian Way \\ Cambridge, MA 02138 \\ dana_mccoy@gse.harvard.edu
}

Wolf, S. \& McCoy, D.C. (2019). The role of executive function and social-emotional skills in

the development of literacy and numeracy during preschool: A cross-lagged longitudinal study.

Developmental Science, 22(4), e12800. https://doi.org/10.1111/desc.12800

Acknowledgements. This paper reflects contributions from many organizations and individuals. First, we would like to thank J. Lawrence Aber and Jere R. Behrman, co-investigators on the original study from which the data was collected; we are grateful for all of their support. Second, we would like to thank the committed staff at Innovations from Poverty Action. We also thank the UBS Optimus Foundation and the World Bank Strategic Impact Evaluation Fund and Early Learning Partnership for direct support for the project from which the data was collected. 


\begin{abstract}
The majority of evidence on the interplay between academic and non-academic skills comes from high-income countries. The aim of this study was to examine the bidirectional associations between Ghanaian children's executive function, social-emotional, literacy, and numeracy skills longitudinally. Children $(N=3,862 ; M$ age $=5.2$ years at time 1$)$ were assessed using direct assessment at three time points over the course of two school years. Controlling for earlier levels of the same skill, early executive function predicted higher subsequent literacy and numeracy skills, and early literacy and numeracy skills predicted higher subsequent executive function, indicating that the development of executive function and academic skills is inter-related and complementary over time. Early literacy and numeracy predicted subsequent social-emotional skills, but early social-emotional skills did not predict subsequent literacy and numeracy skills. The findings provide longitudinal evidence on children's learning and development in West Africa and contribute to a global understanding of the relations between various developmental skills over time.

Keywords: executive function; social-emotional; early academic skills; cross-lagged panel analysis; Ghana; sub-Saharan Africa.
\end{abstract}




\section{Research Highlights}

- Uses cross-lagged panel analysis to examine longitudinal associations between Ghanaian children's executive function (EF), social-emotional (SE), early literacy, and early numeracy skills over two years.

- Earlier EF skills predict subsequent academic skills, and earlier academic skills predict subsequent EF skills.

- Early academic skills predict subsequent SE skills, but early SE skills do not predict subsequent early academic skills.

- This study contributes to a global understanding of the bidirectional relations between developmental skills over time. 


\section{The Role of Executive Function and Social-emotional Skills in the Development of Literacy and Numeracy during Preschool: A Cross-Lagged Longitudinal Study}

As young children transition to school, they draw on a multitude of social, emotional, behavioral, and academic competencies. Evidence suggests that these competencies are interconnected, with non-academic skills such as executive function (EF) and social-emotional (SE) competence supporting children's ability to learn academic content in the classroom. Less is known, however, about whether academic skills support children's growth in EF and SE, or whether there are bidirectional relations between EF and SE skills themselves. Furthermore, the evidence to date on children's early skill development comes almost exclusively from highincome countries. As such, questions remain regarding how academic and non-academic skills develop over time in different cultural contexts or in settings where educational quality and learning levels are low, such as sub-Saharan Africa (Sandefur, 2016).

In this study, we examine the interplay between non-academic skills—namely, EF and SE competencies — and children's early academic skills during the preschool (i.e., pre-primary) years in Ghana. Ghana is a lower middle-income country in West Africa where, despite having free universal preschool and one of the highest preschool enrollment rates on the continent, many young children do not meet basic cognitive and social-emotional milestones (McCoy et al., 2016). Using cross-lagged panel analysis, we examine how EF and SE contribute to prospective learning, and vice versa, over two years of schooling. In doing so, we provide the first longitudinal empirical evidence of the interplay between EF and SE skills and academic growth in sub-Saharan Africa.

\section{Defining and Linking Academic and Non-Academic Skills}


A growing body of research has identified non-academic skills as core to young children's school readiness (Blair, 2002; Duncan et al., 2007; Raver, 2003). In particular, EF skills include the higher-order cognitive processes that help children control impulses, maintain and shift attention, and manipulate information in working memory (Blair, 2000; Miyake et al., 2000). Although many past studies have examined sub-components of EF (e.g., working memory, set shifting, inhibitory control) as distinct subskills (e.g., Bull \& Lee, 2014; Lan, Legare, Ponitz, Li, \& Morrison, 2011), recent research suggests that EF skills in early childhood may be best represented as a unidimensional construct (Garon, Bryson, \& Smith, 2008; Miyake et al., 2000; Willoughby \& Blair, 2016). Accordingly, and in line with previous work (e.g., Welsh, Nix, Blair, Bierman, \& Nelson, 2010), in this study we operationalize EF as a single construct, measured by both inhibitory control and working memory.

SE skills have been defined through several frameworks, but generally include the abilities to recognize and manage emotions, appreciate the perspectives of others, constructively handle interpersonal conflicts, make responsible decisions, and form positive relationships (Ellis et al., 1997; CASEL, 2017). Past research has often focused narrowly on specific SE skills, including prosocial behaviors that foster positive peer and teacher relationships (e.g., helping, sharing, taking turns; Coolahan, Fantuzzo, Menden, \& McDermott, 2000), emotional competencies (e.g., the ability to recognize and regulate emotions; Denham \& Burton, 2003; Greenberg, Kusche, \& Speltz, 1991), and social problem-solving skills (e.g., defining social conflict and generating positive solutions; Ladd, Buhs, \& Seid, 2000). Very little early childhood research, however, has tested the dimensionality of these skills, their relationships with one another, or how they may collectively represent overall SE development (Denham \& Brown, 2010). In this study, we take a broad approach to the measurement of SE skills by 
operationalizing a range of social-emotional competencies-including emotional awareness, perspective taking, constructive conflict resolution, peer relations, and self-awareness-as a unidimensional construct (Pisani, Dowd, \& Borisova, 2018).

Both EF and SE skills have been shown to grow rapidly during the early childhood period, reflecting both increasing environmental demands for these skills (e.g., in the context of preschool classrooms), and children's increasing neurodevelopmental capacity for higher-order thinking (Shonkoff \& Phillips, 2000; Zelazo \& Carlson, 2012). Collectively, SE and EF skills are central to children's academic learning, as they are thought to support students' ability to manage stress, attend to, engage with, and process information in educational settings, and get along with both peers and teachers (Blair, 2000; Ursache, Blair, \& Raver, 2012; Liew, 2011).

Indeed, a broad body of correlational research suggests that children's early EF skills are predictive of their academic outcomes, both cross-sectionally and longitudinally (Blair \& Razza, 2007; Brock, Rimm-Kaufman, Nathanson, \& Grimm, 2009; Bull, Espy, \& Wiebe, Sheffield, \& Nelson, 2011; Matthews, Ponitz, \& Morrison, 2009; McClelland et al., 2007; Ponitz, McClelland, Matthews, \& Morrison, 2009). For example, prior work has shown positive associations between different EF sub-skills and math achievement in preschoolers, including those from non-U.S. settings and low-income backgrounds (e.g., Lan et al., 2011; McClelland et al., 2014; Welsh et al., 2010). In a review the links between EF and math, Bull and Lee (2014) concluded that updating/working memory explains significant variation in math achievement, whereas the findings for shifting and inhibition are less robust. A smaller but growing body of evidence has examined associations between EF and reading outcomes. When analyzing the three components of EF separately, working memory was found to be the best predictor of reading among six- to eight-year-olds in Brazil (Engle de Abreu et al., 2014). Several recent 
studies from Germany have found evidence of bidirectionality between EF (measured as a single latent construct) and young children's language skills, with language being a stronger predictor of EF development than vice versa (Meixner, Warner, Lensing, Schiefele, \& Elsner, 2018; Slot \& von Suchodoletz, 2018).

Correlational research on the links between early SE skills and later learning outcomes is more mixed, with numerous studies showing positive associations (e.g., Arnold, Kupersmidt, Voegler-Lee \& Marshall, 2012; Curby, Brown, Bassett \& Denham, 2015; Graziano, Reavis, Keane, \& Calkins, 2007; Izard et al., 2001; McKown et al., 2015), and others showing no such links (e.g., Duncan et al., 2007). For example, several studies have found associations between preschoolers' emotion knowledge—including both receptive and expressive identification of emotions - and their academic competence across both literacy and numeracy domains (Garner \& Waajid, 2008; Leerkes, Paradise, O'Brien, Calkins, \& Lange, 2008; Rhoades et al., 2011). Similar associations with academic outcomes have been found for prosocial behaviors, including sharing, helping, and cooperating (Bierman, Torres, Domitrovich, Gest, \& Welsh, 2009; Caprara, Barbaranelli, Pastorelli, Bandura, \& Zimbardo, 2000). Nevertheless, Duncan and colleagues (2007) found no links between social skills and later math and reading achievement after controlling for other dimensions of school readiness (e.g., academic performance and attention).

Experimental research provides additional evidence that non-academic skills may play a key role in improving children's learning, with several randomized control trials of SE and EF interventions showing impacts on children's language, literacy, and math outcomes, despite the fact that these academic skills were not directly targeted (Durlak et al., 2011). For example, the Chicago School Readiness Project-which focused on improving low-income preschoolers' selfregulation skills-identified gains in both early literacy and numeracy skills at the end of the 
intervention year (Raver et al., 2011), whereas the Head Start REDI program-which targeted young children's social competence, emotion regulation, and social problem solving skills using the Preschool PATHS curriculum-showed positive impacts on reading outcomes into kindergarten (Nix, Bierman, Domitrovich, \& Gill, 2013).

Although the majority of research examining the associations between non-academic and academic skill development has hypothesized a unidirectional "flow" in which children's early $\mathrm{EF}$ and SE skills lay the foundation for later academic development, emerging evidence suggests that these relations may not be unidirectional. Instead, it is also possible that children's early growth in academic skills predict their later development of SE and EF. In a recent review, Clements, Sarama, and Germeroth (2016) posit that the development of early math skills may also translate into gains in children's skills in EF, as learning math "exercises" children's working memory and logical thinking, both of which are central to EF (Clements, Sarama, \& Germeroth, 2016). Similarly, Hanno, Jones and McCoy (2019) hypothesize that children's early language and literacy skills may also facilitate EF development, citing evidence that linguistic strategies like "self talk" may provide children with basic mental tools for managing and planning behavior (Vygotsky, 1962; Winsler et al., 2000). Experimental evidence evaluating academically-oriented interventions supports these theories. In particular, participation in a math curriculum was found to reduce preschoolers' behavior problems (Dobbs, Doctoroff, Fisher, \& Arnold, 2006), whereas implementation of a language and mathematics curricula as part of the Boston pre-k program improved multiple dimensions of EF (Weiland \& Yoshikawa, 2013). Although less well studied, there is also reason to believe that early language and numeracy skills may facilitate children's SE development (Denham \& Brown, 2010). For example, improved academic outcomes may lead to higher self-confidence and, as a result, 
prosocial behaviors. On the contrary, children who struggle academically may experience negative emotions that may compromise their social-emotional wellbeing. Several studies support these hypotheses. Herbert-Myers and colleagues (2006), for example, found that children's language skills at age three were predictive of social competence at age eight, whereas Miles and Stipek (2006) found negative links between first grade literacy and third grade aggression. Importantly, there is also some evidence to suggest that certain EF sub-skills (e.g., attention) may partially explain the longitudinal links between academic and SE skills (HerbertMyers et al., 2006). Together, these hypotheses are consistent with a cascade model of development (Masten et al., 2005) and dynamic complementarities across ages (Cunha, Heckman \& Schennach, 2010), which posit that early skill development in one domain may "spill over" into skill development in other areas. Yet few studies have examined these hypotheses empirically, and research on the bi-directional, longitudinal associations between $\mathrm{EF}$ and SE and academic skill development is lacking.

Similarly, relatively little work has considered the ways in which EF and SE skills may support one another over time. One study by Valiente and colleagues (2011) found that first graders' effortful control skills (which, like EF, involve higher-order inhibition) were predictive of their social functioning (e.g., social competence) two years later. (Importantly, these gains in social functioning attributable to early effortful control were also found to predict subsequent academic performance, as measured by teacher- and child-reported grades [Valiente et al., 2001], once again supporting the interconnectedness of academic and non-academic competencies.) Additional research has shown cross-sectional and longitudinal associations between EF and SE skills (Razza \& Blair, 2009; Riggs et al., 2006), with a common explanation that well-regulated children are better equipped to engage in positive social interactions and to be viewed as "good 
citizens" by their teachers and peers (Liew, 2011). Less is known, however, about whether SE skills may support EF development over time.

\section{Executive Function and Social-Emotional Development in Developing Countries}

Although a growing body of evidence suggests the importance of EF and SE for supporting learning and academic behavior in the U.S. and high-income countries (e.g., Diamond, 2013), much less is known about how these skills emerge for children living in developing countries. On the one hand, it is possible that EF and SE development look quite different in different parts of the world, both in level and form. For example, there is strong evidence that the high rates of poverty, malnutrition, and other forms of adversity found in developing countries pose substantial risks for young children's development across domains (Black et al., 2017), suggesting that EF and SE skills may be compromised. In addition, research has shown that different cultures may emphasize different competencies as important for success in school and community life (e.g., Henrich, Heine \& Norenzayan, 2010; Serpell, 2011), making it possible that EF and SE are less necessary for learning in developing country classrooms.

On the other hand, it is possible that EF and SE skills are "universal" in their manifestation and relevance for academic skill development. Supporting this hypothesis, results of sustained attention and delay-of-gratification assessments suggest that children in Africa, unlike with other abstract cognitive tests, perform at or above Western norms (Lamm et al., 2018). Furthermore, several studies have shown links between EF and academic outcomes in developing country settings. McCoy, Zuilkowski, Yoshikawa and Fink (2017) for example, found that young Zambian children's EF skills were predictive of their on-time school enrollment. In Albania, children's self-regulation skills were found to be correlated with emergent academic skills (Von Suchodoletz, Uka, \& Larsen, 2015). 
Although less research is available related to SE and academic development in low- and middle-income countries, a recent study in Tanzania suggests that both parents and teachers see social and emotional competencies as central to academic success but have different perceptions about which competencies are most important (Jukes et al., 2018). Another recent study in Ghana found that a teacher training intervention that increased activity-based and child-centered learning improved both social-emotional and academic outcomes for preschool children (Wolf, Aber, Behrman, \& Tsinigo, 2019). These cross-sectional and two-time-point studies provide initial evidence that EF and SE may play a role in children's early development, but—similar to the U.S. literature - do not necessarily consider how these associations unfold over time.

\section{Preschool and Child Development in Ghana}

In the present study, we advance the literature on the links between non-academic and academic skills outside of the U.S. by exploring these longitudinal processes in Ghana. While participation in preschool (or pre-primary school) is on the rise globally, sub-Saharan Africa still has relatively low rates of access and enrollment (21.9 percent; UNESCO, 2015). Ghana is an exception. In 2007, two years of pre-primary (i.e., kindergarten 1 or “KG1” for 4-year-olds, and KG2 for 5-year-olds) education was introduced as part of the country's education reforms, making it part of the universal basic education system. On-age enrollment is around 75 percent (Ghana Ministry of Education, 2016), which is nearly four times higher than average for subSaharan Africa. Enrollment rates are as high as 94 percent in some communities (Bidwell, Perry, \& Watine, 2014). In this paper, we refer to these two years of schooling as preschool.

Importantly, despite the fact that social, emotional, and behavioral skills are listed as priority areas in Ghana's national KG curriculum (Ghana Education Service, 2004), supporting children's skill development in these areas is rarely practiced (Ghana Education Service, 2012; 
Agbenyega, 2018). It is estimated that approximately one-third of Ghanaian preschool-aged children do not meet basic developmental milestones such as following directions, working independently, and getting along with others (McCoy et al., 2016). Indeed, the early childhood education system in Ghana tends to focus primarily on academic skill development (Agbenyega, 2018), reflecting the demands of many African parents for schools that are highly structured and “academically rigorous" (Bidwell et al., 2014; Jukes et al., 2018). Researchers have raised concerns that the "traditional" approaches to education that are used to promote academic growth in African societies (e.g., rote instruction and memorization) may be developmentally inappropriate for young children (Choi, 2006; Osei, 2006). These practices are in contrast to "modernist" approaches to early education (i.e., child-centered, activity- and play-based approaches) that address social skills and the unique needs of very young children (Hirsh-Pasek, 2009).

Despite this academic focus, learning outcomes are also low in Ghana (RTI International, 2016). Collectively, this evidence suggests that one mechanism for promoting children's early academic skills in Ghana may be through supporting early EF and SE development.

Nevertheless, more evidence is needed regarding the links between these skills in this particular context prior to encouraging broad-scale curricular changes.

\section{The Present Study}

The objective of this study is to use longitudinal data to examine how preschool children's non-academic (EF and SE) skills both predict and are predicted by their academic learning (literacy and numeracy). We examine how cross-domain development unfolds over time during a particularly sensitive developmental period of early childhood in the under-studied context of Ghana. Drawing on developmental "cascade" (Masten et al., 2005) and models of 
dynamic learning complementarities across ages (Cunha et al., 2010), as well as prior research from high-income contexts, we hypothesize strong associations between early non-academic and prospective academic outcomes, and significant but smaller associations between early academic outcomes and prospective non-academic outcomes. Similarly, based on research from highincome countries, we hypothesize that early EF will predict subsequent SE, whereas the reverse relation (early SE predicting later EF) will be substantially less robust.

This study contributes to the knowledge base on the universality of EF and SE skills, and the role they play in children's learning across contexts. In addition, the findings can inform educational intervention and policy efforts designed to promote young children's learning and development by providing evidence of the broader skills children draw upon as they learn academic content. In particular, the results contribute to the evidence base on the importance of promoting social, emotional, cognitive, and behavioral skills for preschool children globally. This study also serves as the first cross-lagged longitudinal analysis of both EF and SE skills in early childhood in sub-Saharan Africa. Our objective is to expand a robust body of literature from high-income countries to a population of children who stand ready to benefit from highquality early-education services, and to inform teacher professional development efforts as countries across Africa expand their preschool systems.

\section{Methods}

\section{Participants and Procedure}

Data come from an impact evaluation study of the Quality Preschool for Ghana project (Wolf et al., 2019), which tested the impacts of a teacher in-service training and parental awareness program in six districts in the Greater Accra Region of Ghana. The interventions were implemented during the 2015-2016 school year, and data were collected at three time points: 
September 2015 (“time 1"), June 2016 (“time 2"), and June 2017 (“time 3"). Schools (N=240) were randomly assigned to one of three treatment arms: (a) Teacher-training and coaching (82 schools), (b) Teacher-training and coaching plus parental awareness meetings (79 schools), and (c) control group (79 schools). Impacts of the program have been presented in other papers (Wolf et al., 2019; Wolf, Aber, Behrman \& Peele, 2019; Wolf \& Peele, 2019).

All schools in the six districts were identified using the Ghana Education Service Educational Management Information System (GES-EMIS) database, which listed all registered schools in the country. Schools were randomly sampled from the list, stratified by district and by public and private schools. A school census was then conducted to confirm the presence of each school and to obtain information on each school's head teacher and proprietor. Because there were fewer than 120 public schools across the six districts, every public school was sampled. Private schools (490 total) were sampled in proportion to the total number of private schools in each district relative to total for all districts.

At time 1, passive consent of all Kindergarten $1(\mathrm{KG} 1)$ and Kindergarten 2 (KG2) children in the selected schools was sought via forms sent home to caregivers. Ten caregivers refused their children's participation. Of the rest, 15 children ( 8 from KG1, $M$ age $=4.7$ years in the fall; and 7 from $\mathrm{KG} 2, M$ age $=5.8$ years) were randomly selected from each class roster to participate in direct assessments. A small percentage of schools (10\%) had one combined KG classroom rather than two separated by levels. In these schools, 15 children were randomly selected from the combined class. In schools with fewer than $15 \mathrm{KG}$ children, all children were sampled.

School mobility is common in Ghana, with children often moving to live with extended family in the middle of a school year for educational or economic reasons. We made three 
attempts to follow up with each child in the sample, including trying to locate them in new schools as long as they were in the Greater Accra Region. Nevertheless, attrition did occur. As such, at time 2, 432 children were added to the sample based on two scenarios: (1) to replace children who had left the school with children from the existing classroom roster, and (2) to add children to schools that had fewer than $15 \mathrm{KG}$ children in the fall where enrollment increased by the spring. At time 3, considerable effort was made to include all children from the time 1 and 2 samples, even if they were not available the previous wave. In total, 3,867 children were sampled across all three waves. Five of the sampled children were missing data at every wave, resulting in a final analytic sample of 3,862 children. Over two-thirds of the sample $(68.8 \% ; N=2,657)$ had data at all three time points; $20.3 \%(N=782)$ had data at two of the three waves, and $11.0 \%(N=$ 423) had data at one wave. Approximately half of children (50.8\%) were male, and the average age at time 1 was 5.23 years $(S D=1.37)$. The sample was balanced in terms of demographic characteristics across treatment and control groups (Wolf et al., 2019). See Table 1 for additional sample descriptive statistics.

Children's skills were assessed directly by trained, multi-lingual data collectors in children's school environments using the language(s) with which each child was most comfortable (Twi/Fanti only: 39.0\%; Ewe only: 1.3\%; Ga only: 5.0\%; English only: 37.9\%; and mixed English and local language: 16.9\%). Data collectors had prior experience working with children and completed a five-day training by a certified Master Trainer. Their inter-rater reliability was calculated during field-based practice sessions, resulting in an average kappa value of .87 across the four developmental domains (kappa $=.82$ for social-emotional; .86 for early numeracy; .90 for early literacy; and .88 for executive function). Children's demographic 
characteristics were reported by their primary caregiver (41.6\% mothers, $44.6 \%$ fathers, and $13.8 \%$ other) at time 1 , and/or taken from school records.

\section{Measures}

All child non-academic and academic skills were measured via direct assessment at each of the three time points using the International Development and Early Learning Assessment (IDELA; Pisani et al., 2018; Wolf et al., 2017). The IDELA was designed for use in global, lowresourced settings to broadly measure multiple developmental domains and was derived from several commonly used assessments of school readiness, including the Early Development Instrument (EDI; Janus et al., 2007), the Ages and Stage Questionnaire (ASQ; Squires \& Bricker, 2009), the Malawi Development (MDAT; Gladstone et al., 2010), and the East Asia Pacific-Early Child Development Scales (EAP-ECDS; Rao et al., 2014). See Pisani and colleagues (2018) for a detailed accounting of the development of IDELA and Halpin and colleagues (2019) for an examination of its measurement properties across multiple countries.

The version used in the present study was reviewed by Ghanaian child development experts and piloted with 20 children to ensure cultural applicability. Very few changes were made. The few minor changes were related primarily to word choice (e.g., simplifying instructions and/or removing redundant words). Scoring rules for two of the prosocial items were changed to allow children to receive a "correct" score for more than one response that local experts decided to be relevant within the local context. Translations of the tool from English into the three local languages (Twi/Fanti, Ewe, Ga) were conducted using forward and backward translation by different individuals, followed by separate conversations with local experts to resolve discrepancies and confirm accuracy. (For details about IDELA scoring, see Pisani et al., 2018). We examined the distributions of all variables across time and found them to be normally 
distributed (see Appendix Figure 1).

Two recent studies examined the construct validity of IDELA and are worth noting. Wolf and colleagues (2017) found strong support for a four-factor model (including items measuring motor skills but not EF), compared to other alternative factor structures in Ethiopia. A follow-up study replicated the factor structure in four additional low- and middle-income countries and found evidence of partial measurement invariance for each domain across the four countries (Halpin et al., 2019). Accordingly, in this study we operationalize each domain — numeracy, literacy, EF, and SE—as a unidimensional construct.

Early numeracy. The early numeracy subscale of the IDELA included 39 items measured via eight subtasks that assessed children's number knowledge, basic addition and subtraction, one-to-one correspondence, shape identification, sorting abilities based on color and shape, size and length differentiation, and completion of a simple puzzle $(\alpha=0.72,0.70$ and 0.72 at times 1,2, and 3, respectively). For example, to assess children's one-to-one correspondence, children were provided a pile of beans and asked by the assessor to hand him/her a certain number of beans (e.g., 3, 8). A second example examining size and length differentiation displayed two pictures of (i) three circles, and (ii) three sticks. Children were asked to identify the biggest and smallest circles in the first picture, and the shortest and longest sticks in the second picture. Scores for each subtask were calculated as the proportion of items correct, with a possible range from 0 to 1 , and averaged across all subtasks.

Early literacy. Children's early literacy was measured using 38 items measured via six subtasks that reflected children's print awareness, letter knowledge, phonological awareness, oral comprehension, emergent writing, and expressive vocabulary $(\alpha=0.74,0.72$, and 0.88 at each of the three time points, respectively). For example, for letter knowledge, children were shown a 
series of letters. The assessor pointed to each letter one at a time and asked the child, "what letter is this?" Children were asked to identify 20 letters, with the first 10 high frequency letters, and the second 10 lower frequency letters. A second example subtask on phonological awareness asked children to identify words that begin with the same sound. A sample item is: "Here is my friend mouse. Mouse starts with $/ \mathrm{m} /$. What other word starts with $/ \mathrm{m} /$ ? Cow, doll, milk". Scores for each subtask were calculated as the proportion of items correct, with a possible range from 0 to 1 , and averaged across all subtasks.

Executive function. Executive function was captured using ten items measured via two subtasks measuring children's working memory (e.g., forward digit span) and inhibitory control (e.g., head-toes task adapted from McClelland et al. (2014); $\alpha=0.84,0.83$ and 0.79, respectively). Scores for each subtask were calculated as the proportion of items correct, with a possible range from 0 to 1 , and averaged across all subtasks.

Social-emotional skills. Social-emotional competence was measured using 14 items via five subtasks that capture children's self-awareness, emotion identification, perspective-taking and empathy, friendship, and conflict/problem solving ( $\alpha=0.69,0.70$, and 0.67, respectively). For perspective taking and empathy, for example, children were shown a drawing of a crying girl and asked to answer questions such as, "how do you think this child is feeling right now?" and “what would you do to help her feel better?” A second example is conflict resolution. Children were asked what they would do if they were playing with a toy and another child wanted to play with the same toy. "Correct" answers, as agreed upon with local staff, included talking to the child, taking turns, and sharing. Up to three answers were scored. Scores for each subtask were calculated as the proportion of items correct, with a possible range from 0 to 1 , and averaged across all subtasks. 
Covariates. In addition to controlling for time 1 IDELA scores, several additional covariates were used in the analyses to account for possible confounding characteristics. Children's age and gender were reported by primary caregivers at time 1 and confirmed by data collectors during the child assessment. Primary caregivers also reported on the number of books in the home, and a set of ten household variables (e.g., number of household members, highest grade completed by female head or spouse, employment of male head of house, materials used for construction of household's roof, source of drinking water, possession of materials such as working radio). These ten variables were combined to construct the Simple Poverty Scorecard for Ghana (Schreiner \& Woller, 2010), a validated metric of household poverty levels for Ghana that ranges from 0 to 100 (with lower scores indicating less wealth / higher poverty). Four additional school-related characteristics were included: an indicator for whether the school was private (vs. public), an indicator for the grade level of the child (KG1, KG2, or a mixed $\mathrm{KG} 1 / \mathrm{KG} 2$ classroom), a set of indicators for the school's district, and treatment assignment at baseline. Classroom quality was also included in a sensitivity analysis and was measured at each time point using the Teacher Instructional Practices and Processes System (TIPPS; Seidman et al., 2013), an observational measure designed to capture the nature of teacher-child interactions in low-resourced settings. We averaged scores on teachers' (1) facilitation of deeper learning practices, (2) support for student expression, and (3) emotional climate and behavior management practices (see Wolf et al., 2018), for a detailed measurement analysis of the TIPPS items and the three domains of classroom quality in the present dataset).

\section{Analytic Plan}

We used cross-lagged panel analysis — a form of path analysis - to examine relations between children's non-academic and academic skills over time. In particular, we accounted for 
auto-lagged pathways between the same domains measured across time (e.g., EF at time 1 predicting EF at time 2; EF at time 2 predicting EF at time 3), as well as cross-lagged pathways between different domains across time (e.g., EF at time 1 predicting literacy at time 2; literacy at time 2 predicting EF at time 3). We also included the covariates listed above as predictors of all time 2 and time 3 skills. To better account for potential measurement error, we included error covariances across domains at each time point. Full-information maximum-likelihood (FIML) was used to account for missing data on child outcomes and covariates, conditional on all other variables in the model (see Table 2 for the observed sample size at each time point). We also used a maximum-likelihood estimator with robust standard errors (MLR) to account for children nesting within schools. We used the following criteria to establish model fit: a non-significant model chi square, a Comparative Fit Index (CFI) and Tucker Lewis Index (TLI) of >.90, and a Root Mean Square Error of Approximation (RMSEA) and a Standardized Root Mean Square Residual (SRMR) of <.08 (Hu \& Bentler, 1999; Kline, 2015). All analyses were conducted in Mplus (version 6.2; Muthén \& Muthén, 1998-2012).

Sensitivity analyses. Four sets of sensitivity analyses were run to assess the robustness of the findings across different model and sample specifications. First, we included time-varying estimates of classroom quality as an additional predictor variable in our primary model, within our full sample. Second, we restricted our sample only to those children with at least two waves of complete data. Third, to determine whether there may be differences in developmental processes dependent on grade level (a proxy for both child age and schooling experience), we compared results of our primary model in which parameters were fixed across KG1 and KG2 students to an alternative model in which parameters were allowed to vary across these groups. Finally, to ensure that results were not attributable to children's intervention status, we compared 
our primary model to one in which all parameters were allowed to differ across the treatment and control groups. For both of these latter models, we used a chi square difference test to determine whether there were significant overall differences in model fit across subgroups.

\section{Results}

The main model was a cross-lagged path model for the full sample of children $(N=$ 3,862 ). The goodness of fit statistics for the model were adequate: $\mathrm{CFI}=.98, \mathrm{TLI}=.96, \mathrm{RMSEA}$ $=.021, \mathrm{SRMR}=.047$, and $\chi^{2}(141)=376.89, p<.001$. All standardized and unstandardized path coefficients for the primary model are presented in Table 3, and significant standardized coefficients are displayed in Figure 1.

The strongest predictor of each skill, with one exception, was the same skill from the previous wave. The magnitude of auto-lagged coefficients was roughly the same size across time 1 to time 2 , and time 2 to time 3 (for numeracy: $b_{t 1-12}=0.48$, S.E. $=0.02, p<.001 ; b_{\mathrm{t} 2-\mathrm{t} 3} 0.41$, S.E. $=0.02, p<.001 ;$ for literacy: $b_{\mathrm{t} 1-\mathrm{t} 2}=0.31$, S.E. $=0.02, p<.001 ; b_{\mathrm{t} 2-\mathrm{t} 3}=0.39$, S.E. $=0.02, p$ $<.001$; for executive function: $b_{\mathrm{t} 1-\mathrm{t} 2}=0.22$, S.E. $=0.02, p<.001 ; b_{\mathrm{t} 2-\mathrm{t} 3}=0.24$, S.E. $=0.02, p<$ .001 ; and for social-emotional: $b_{\mathrm{t} 1-\mathrm{t} 2}=0.27$, S.E. $=0.02, p<.001 ; b_{\mathrm{t} 2-\mathrm{t} 3}=0.29$, S.E. $=0.02, p<$ $.001)$.

There was also evidence for positive cross-lagged associations across developmental domains. Within the academic domain, there were cross-lagged associations between literacy and numeracy at both time points. Specifically, literacy at time 1 predicted higher numeracy at time $2, b=0.15$, S.E. $=0.02, p<.001$, and literacy at time 2 predicted higher numeracy at time 3 , $b=0.18, \mathrm{~S} . \mathrm{E}=0.02, p<.001$. Similarly, numeracy at time 1 predicted higher literacy at time 2, $b=0.33$, S.E. $=0.02, p<.001$, and numeracy at time 2 predicted higher literacy at time $3, b=$ 
0.27 , S.E. $=0.02, p<.001$. Notably, the cross-lagged association from numeracy to literacy skills was larger in magnitude than the cross-lagged association from literacy to numeracy skills.

We also found evidence for cross-lagged associations between non-academic and academic skills. In particular, we identified associations between early EF and later literacy and numeracy skills that were similar in magnitude across time and roughly one-fifth to one-half the size of the cross-lagged associations between literacy and numeracy. Specifically, EF at time 1 predicted higher literacy $(b=0.06$, S.E. $=0.02, p<.001)$ and numeracy at time $2(b=0.08$, S.E. $=0.01, p<.001)$, and EF at time 2 predicted higher literacy $(b=0.06$, S.E. $=0.02, p<.001)$ and numeracy at time $3(b=0.09$, S.E. $=0.02 p<.001)$. We did not find evidence for a cross-lagged association between earlier SE and later academic skills.

We also found evidence of cross-lagged associations in which early literacy and numeracy skills predicted later EF and SE. These cross-lagged paths from early academic to later non-academic skills were one-quarter to three times larger than those leading from early nonacademic skills to later academic skills. Specifically, literacy at time 1 predicted higher EF ( $b=$ 0.10 , S.E. $=0.02, p<.001)$ and SE at time $2(b=0.12$, S.E. $=0.02, p<.001)$, and literacy at time 2 predicted higher $\mathrm{EF}(b=0.14$, S.E. $=0.02, p<.001)$ and $\mathrm{SE}$ at time $3(b=0.12$, S.E. $=$ $0.02, p<.001)$. Similarly, numeracy at time 1 predicted higher $\mathrm{EF}(b=0.20$, S.E. $=0.02, p<$ $.001)$ and SE at time $2(b=0.12$, S.E. $=0.03, p<.001)$, and numeracy at time 2 predicted higher $\mathrm{EF}(b=0.16$, S.E. $=0.02, p<.001)$ and SE at time $3(b=0.11$, S.E. $=0.02, p<.001)$.

Finally, we found minimal evidence for cross-lagged associations within the nonacademic domain between EF and SE skills. In particular, only EF at time 1 was found to be marginally predictive of SE at time $2, b=0.03$, S.E. $=0.02, p<.10$.

\section{Sensitivity Analyses}


Four sets of sensitivity analyses were run to assess the robustness of the findings across different model and sample specifications. (See Appendix Table 1 for details.) First, we included time-varying estimates of classroom quality as an additional predictor variable in our primary model. Second, we restricted our sample only to those children with at least two waves of complete data. For these analyses, we compared the magnitudes and directions of our coefficients of interest against those of our primary model. We found that results were highly similar in each case.

Third, to probe for differences across subgroups (i.e., treatment status, KG level), we used the chi square difference test to compare our primary model in which parameters were constrained to be equal across groups to one in which all parameters were allowed to differ. In the case of treatment status, the chi square difference test was non-significant $\left(\chi^{2}\right.$ diff $(113)=$ $67.52, p=.999)$, indicating that the model in which parameters were allowed to vary across the treatment and control groups did not fit the data better than the primary model. As such, we concluded that there was no evidence for variation in the relations between developmental domains based on treatment status. Fourth, we compared our primary model to one in which all parameters were allowed to differ for children in KG1 versus KG2 in the first year of the study. In this case, we rejected the hypothesis that the primary, more parsimonious model provided equivalent fit to the data $\left(\chi^{2}\right.$ diff $\left.(127)=154.51, p<.01\right)$, suggesting that there are differences in how these variables relate over time for these two groups. Table 4 presents the results for each group separately. While the overall pattern of associations was similar across the two groups, the magnitudes of the coefficients are slightly larger for KG1 students, particularly for literacy and numeracy outcomes.

\section{Discussion}


The primary aim of this study was to examine the pattern of associations between academic (literacy and numeracy) and non-academic (executive function and social-emotional) skills across three time points in an under-studied population of preschoolers living in peri-urban communities in Ghana. Specifically, we examined whether and how the specific non-academic skills assessed (SE and EF) predicted prospective academic learning outcomes, whether and how academic skills predicted prospective EF and SE, and whether and how EF and SE related to one another over time. Our results revealed consistent evidence for small to moderate bidirectional relations between developmental domains, providing support for dynamic and holistic theories of young children's development and school readiness. These findings were particularly strong for younger children starting their first year of basic education, highlighting the interdependent nature of skill development in children's transition to school.

\section{Links between Early EF and SE and Later Academic Skills}

We found that while the strongest predictors of young children's academic development over time appear to be their prior respective academic skill levels $(\beta=0.31-0.48)$, executive function has considerable predictive power for children's early learning in Ghana. Indeed, EF skills predicted unique variance in prospective academic outcomes of about one-third the magnitude of the respective previous academic skills $(\beta=0.06-0.09)$. This suggests that children's ability to hold information in their working memory and inhibit impulsive reactions may be foundational "domain-general" skills for acquiring academic knowledge in Ghanaian classrooms, just as they have found to be in the U.S. (e.g., Duncan et al., 2007, Blair \& Razza, 2007).

Whereas EF appears to play a central role in supporting growth in children's literacy and numeracy skills, SE skills were not found to predict later academic development. Importantly, 
the majority of evidence linking SE skills to academic skills has focused on elementary schoolaged children (e.g., Durlak et al., 2011; Taylor et al., 2017). Research on younger children has found relatively mixed results on the links between early SE skills and later learning outcomes (e.g., Arnold et al., 2012; Duncan et al., 2007). Our findings complement this body of research, and also may reflect the educational and cultural context experienced by children in Ghana. In particular, the Ghanaian education system places a strong emphasis on children's compliance and obedience, and instruction and classroom management are accordingly highly teacherdirected (Agbenyega, 2018; Akyeampong, 2017). As such, it is possible that children's EF skills are particularly relevant in Ghana to support the obedience and compliance that likely facilitate learning in a teacher-directed context, whereas SE skills such as getting along with others, identifying emotions, and solving social conflicts are less relevant for learning under these circumstances.

Alternatively, it is possible that our measure of SE skills did not adequately capture the social competencies most important in the Ghanaian context. In Africa, in particular, scholars have noted the importance of the social ontogenetic paradigm (Nsamenang, 2005), with socialization organized to teach shared responsibly within the family and community (rather than for individualization or academic pursuits; Nsamenang \& Lamb, 1994). This emphasis on social and emotional competence is shared by African parents, who often cite respect and social compliance as core values that they hope schooling to instill in their children (Jukes et al., 2018). The tool used to measure SE in the present study - the IDELA — was designed for global use, yet is grounded in Western constructs of social and emotional skills (Pisani et al., 2018). Although the IDELA has been found to demonstrate measurement invariance across five diverse countries in three regions (Halpin et al., 2019), it does not necessarily capture the full range of social and 
emotional competencies that may be important for school success in the Ghanaian cultural context. A measure that specifically operationalizes children's competence in interpersonal relationships within the Ghanaian classroom context may identify skills necessary for learning that are not captured by IDELA.

\section{Links between Early Academic Skills and Later EF and SE}

One contribution of this study is our examination of whether and how academic skills predict prospective EF and SE skills over time, a question that has been under-examined in the literature to date. We find that early literacy and numeracy skills do indeed predict children's prospective EF and SE skills, and that the magnitude of these relations is even larger $(\beta=0.12-$ $0.22)$ than that of EF predicting both literacy and numeracy $(\beta=0.06-0.09)$. A recent study among preschoolers in Germany found very similar results; children's language skills were a stronger predictor of their subsequent EF skills than the other way around (Slot \& von Suchodoletz, 2018). These findings support a developmental cascades model (Masten \& Cicchetti, 2010), which refers to the cumulative consequences of the many interactions and transactions for development that "spill over" across domains. The results from both studies suggest that across different contexts, the relative strength of cross-domain associations may be consistent.

Future research is needed to understand the mechanisms through which these particular cascades may operate. At the most basic level, it is possible that the improved language and reasoning skills that often underlie academic gains could be central to children's ability to develop - and demonstrate - more advanced EF and SE skills. Social problem solving, for example, may draw from the same skillset as academic problem solving, requiring children to identify the component parts of the challenge, and to plan and enact an appropriate solution. 
Alternatively, it is possible that improvements in academic performance may build children's feelings of self-esteem and self-efficacy (e.g., Zimmerman, 2000), which may help to support their growth in EF and SE. Finally, it may be possible that it is not academic skills themselves that support children's SE and EF development; rather, children's parents, teachers, or peers may respond to improved literacy and numeracy skills in ways that also support EF and SE development. For example, in Ghana, improved academic skills may make it less likely that teachers will cane (physically punish) a child for an incorrect answer to a question (Agbenyega, 2018). Given that stress is a known risk factor for both EF and SE development (Blair, 2010), it is possible that simply removing the threat of punishment as the result of improved academic skills could also indirectly support children's non-academic growth, as well.

\section{Links within Academic and Non-Academic Skills Over Time}

We also explored the possibility for within-domain relations. No significant associations were observed between EF and SE skills. The absence of significant relations within skills in the non-academic domain is in keeping with the above evidence on the lack of prospective association between early SE and later academic skills. In particular, whereas it is possible that these skills develop on independent trajectories across the developmental continuum, it is also likely that we have not fully captured all forms or representations of these skills relevant to the Ghanaian context. Future work is needed to explore similar relations using expanded measurement approaches in diverse parts of the world (e.g., Jukes et al., 2018).

Within the academic domain, however, we observe strong bidirectional links between children's literacy and numeracy skills. Notably, the relations between numeracy skills and subsequent literacy skills ( $\beta=0.33$ for time 1 to 2 and 0.33 for time 2 to 3 ) were larger in magnitude than the reverse ( $\beta=0.15$ for time 1 to $2,0.22$ for time 2 to 3 ). These findings are 
consistent with longitudinal descriptive research of several nationally representative samples in the U.S. showing that early math skills have greater predictive power on later achievement than do early reading skills (e.g., Duncan et al., 2007), and further reinforce the importance of integrating practices that promote math instruction in early educational settings (Clements \& Sarama, 2011).

\section{Limitations and Future Research}

These findings must be interpreted within the study's limitations. First, while this study was conducted in a population under-represented in developmental science research, the findings cannot be generalized outside of the peri-urban Greater Accra Region without further investigation. There are large differences in the risk and protective factors experienced by children living in urban and rural settings (Zhang, 2006), and in Ghana specifically (Cooke et al., 2016), that may affect how children's academic and non-academic skills interplay. Additional research is needed to understand the external validity of these associations in diverse contexts, in particular across sub-Saharan Africa.

Second, the same measures were used at each of the three time points. Although this allowed us to directly compare these skills over time — a strength of the study design — it also means that as children grew, the distribution of skills, in particular EF skills, became negatively skewed. While the skewness statistic for all outcomes at each time point was below an absolute value of one, adaptive measures may have been more sensitive to capturing change and growth. Similarly, as noted above, despite the fact that the measure used in this study was intentionally designed and validated for use in low-resource, international contexts, it was also largely developed using a broad, Western perspective on children's development. Future work using expanded measurement batteries is needed to explore the interplay between more narrowly 
defined developmental processes that are known to be salient within the Ghanaian cultural context (e.g., obedience, respect, social responsibility), but that were not necessarily captured here. Doing so will also allow for a more nuanced understanding of the specific developmental sub-skills that may be driving patterns of relations over time.

Third, extensive research using well-established measurements has examined the components and factor structure of EF and SE skills across different stages of childhood in highincome countries (e.g., Miyake et al., 2000). Similar work does not yet exist in sub-Saharan Africa, and thus we do not have a strong psychometric evidence base from which to operationalize SE and EF constructs in this sample. We follow two recent studies that support a unidimensional operationalization of literacy, numeracy, SE, and EF skills using the items from the IDELA (Halpin et al., 2019; Wolf et al., 2017), a newly available tool specifically designed for measurement of early development in resource-limited settings. Nevertheless, we acknowledge that future work is needed to examine the components and factor structure of these domains in sub-Saharan Africa. Furthermore, additional measurement work is needed to establish — and improve — the psychometric properties of tools used for measuring early development in culturally and linguistically diverse settings, as well as to develop and validate test norms for examining children's developmental progress over time.

Finally, although our use of auto-lagged pathways to account for time-invariant characteristics and our inclusion of a broad set of covariates lessens possible issues of selection bias, the results of this study cannot be considered as fully causal. As we note throughout our discussion, it is likely that unobserved characteristics - either of children's environments or their own skills - may partially or fully explain the observed associations between the developmental skills captured in this study. As has been noted extensively by others (e.g., Clements et al., 2016; 
Jacob \& Parkinson, 2015), additional research using experimental designs targeting only one skill domain at a time is necessary for establishing causal linkages over time.

\section{Conclusion and Implications}

Results from this study advance a growing body of research demonstrating the importance of social, emotional, and higher-order cognitive aspects of development for early academic skills and school success. Indeed, more studies are highlighting the importance of examining multiple school readiness domains simultaneously rather than separately (e.g., Pace, Burchinal, Alper, Hirsh-Pasek, \& Golinkoff, 2018). The field of education must also move beyond skill-levels at a particular grade to skill acquisition both within- and across-domains. As close to ninety percent of children in the world live in a low- or middle-income country (World Bank, 2016), and these children are attending preschool at growing rates (Behrman et al., 2013; McCoy et al., 2018), research examining children's transition to schooling in developing countries is needed. These results can provide some direction on how to best target early skills via preschool curricula and early intervention to support children's development across diverse contexts. Furthermore, understanding how non-academic and academic skills unfold over time in cultures that focus on integrating children in to hierarchical social networks (e.g., Lamm et al., 2018), as in the case in Ghana, contribute to a cross-cultural research program that is critical for understanding child development from a global perspective. Such a program of research is needed to support global efforts to improve educational quality and child development. 


\section{References}

Agbenyega, J. S. (2018). Examining early childhood education system in Ghana: How can Bourdeuian theorization support a transformational approach to pedagogy? In M. Fleer, \& B. Oers (Eds.). International Handbook of Early Childhood Education (Vol. 1, pp. 673705). Springer.

Akyeampong, K. (2017). Teacher educators' practice and vision of good teaching in teacher education reform context in Ghana. Educational Researcher, 46(4), 194-203.

Arnold, D. H., Kupersmidt, J. B., Voegler-Lee, M. E., \& Marshall, N. A. (2012). The association between preschool children's social functioning and their emergent academic skills. Early Childhood Research Quarterly, 27(3), 376-386.

Behrman, J. R., Fernald, L., \& Engle, P. (2013). Preschool programs in developing countries. Education Policy in Developing countries, 65-105.

Bidwell, K., Perry, K., \& Watine, L. (2014). Exploring early education programs in peri-urban settings in Africa: Accra, Ghana. New Haven, CT: Innovations for Poverty Action.

Bierman, K. L., Torres, M. M., Domitrovich, C. E., Gest, S. D. and Welsh, J. A. 2009. Behavioral and cognitive readiness for school: Cross-domain associations for children attending Head Start. Social Development, 18: 305-323.

Black, M. M., Walker, S. P., Fernald, L. C., Andersen, C. T., DiGirolamo, A. M., Lu, C., ... \& Devercelli, A. E. (2017). Early childhood development coming of age: science through the life course. The Lancet, 389(10064), 77-90.

Blair, C. (2002). School readiness: Integrating cognition and emotion in a neurobiological conceptualization of children's functioning at school entry. American Psychologist, 57(2), $111-127$.

Blair, C. (2010). Stress and the development of self-regulation in context. Child Development 
Perspectives, 4(3), 181-188.

Blair, C., \& Razza, R. P. (2007). Relating effortful control, executive function, and false belief understanding to emerging math and literacy ability in kindergarten. Child development, 78(2), 647-663.

Bull, R., Espy, K. A., Wiebe, S. A., Sheffield, T. D., \& Nelson, J. M. (2011). Using confirmatory factor analysis to understand executive control in preschool children: Sources of variation in emergent mathematic achievement. Developmental Science, 14(4), 679-692.

Bull, R., \& Lee, K. (2014). Executive functioning and mathematics achievement. Child Development Perspectives, 8(1), 36-41.

Caprara, G.V., Barbaranelli, C., Pastorelli, C., Bandura, A., \& Zimbardo, P.G. (2000). Prosocial foundations of children's academic achievement. Psychological Science, 11(4), 302-306.

CASEL. (2017). Core SEL Competencies. Retrieved from http://www.casel.org/core-competencies/.

Choi, S. (2006). Bite off only as much as you can chew': Gambia's policy of early childhood development. Policy brief on early childhood development. No 34, Paris: UNESCO.

Clements, D. H., \& Sarama, J. (2011). Early childhood mathematics intervention. Science, 333(6045), 968-970.

Clements, D. H., Sarama, J., \& Germeroth, C. (2016). Learning executive function and early mathematics: Directions of causal relations. Early Childhood Research Quarterly, 36, 79-90.

Cooke, E., Hague, S., \& McKay, A. (2016). The Ghana poverty and inequality report: Using the 6th Ghana living standards survey. University of Sussex.

Coolahan, K., Fantuzzo, J., M?ndez, J., \& McDermott, P. (2000). Preschool peer interactions and readiness to learn: Relationships between classroom peer play and learning behaviors and conduct. Journal of Educational Psychology, 92, 458-465.

Curby, T.W., Brown, C.A., Bassett, H.H., \& Denham, S.A. (2015). Associations between 
preschoolers' social-emotional competence and preliteracy skills. Infant \& Child Development, 24(5), 549-570.

Cunha F., Heckman, J.J., \& Schennach, S.M. (2010). Estimating the technology of cognitive and noncognitive skill formation. Econometrica, 78(3), 883-931.

Denham, S. A., \& Brown, C. (2010). "Plays nice with others": Social-emotional learning and academic success. Early Education and Development, 21(5), 652-680.

Denham, S. A., \& Burton, R. (2003). Social and emotional prevention and intervention programming for preschoolers. New York: Kluwer-Plenum.

Diamond, A. (2013). Executive functions. Annual Review of Psychology, 64, 135-168.

Dobbs, J., Doctoroff, G. L., Fisher, P. H., \& Arnold, D. H. (2006). The association between preschool children's socio-emotional functioning and their mathematical skills. Journal of Applied Developmental Psychology, 27(2), 97-108. doi: 10.1016/j.appdev.2005.12.008

Duncan, G. J., Dowsett, C. J., Claessens, A., Magnuson, K., Huston, A. C., Klebanov, P., ... \& Sexton, H. (2007). School readiness and later achievement. Developmental Psychology, $43(6), 1428$.

Ellis, C. R., Lindstrom, K. L., Villani, T. M., Singh, N. N., Best, A. M., Winton, A. S., ... \& Leung, J. P. (1997). Recognition of facial expressions of emotion by children with emotional and behavioral disorders. Journal of Child and Family Studies, 6(4), 453-470.

Engel de Abreu P., Abreu N., Nkaedo C., Puglisi M., Tourinho, de Abreu Neto C. J. et al. (2014). Executive functioning and reading achievement in school: a study of Brazilian children assessed by their teachers as "poor readers". Frontiers in Psychology, 5, 550.

Garner, P. and Waajid, B. I. 2008. The associations of emotion knowledge and teacher-child relationships to preschool children's school-related developmental competence. Journal of Applied Developmental Psychology, 29, 89-100. 
Garon, N., Bryson, S. E., \& Smith, I. M. (2008). Executive function in preschoolers: a review using an integrative framework. Psychological Bulletin, 134(1), 31-60.

Ghana Education Service (2004). WSD Status Report. Ministry of Education. Accra, Ghana.

Ghana Education Service. (2012). Programme to scale-up quality kindergarten education in Ghana. Accra, Ghana: Ghana Ministry of Education. Ministry of Education. Accra, Ghana.

Ghana Ministry of Education (2016). Education Sector Performance Report 2016. Ghana

Gladstone, M., Lancaster, G. A., Umar, E., Nyirenda, M., Kayira, E., van den Broek, N. R., \& Smyth, R. L. (2010). The Malawi Developmental Assessment Tool (MDAT): the creation, validation, and reliability of a tool to assess child development in rural African settings. PLoS medicine, 7(5), e1000273.

Graziano, P. A., Reavis, R. D., Keane, S. P., \& Calkins, S. D. (2007). The role of emotion regulation in children's early academic success. Journal of School Psychology, 45(1), 3-19.

Greenberg, M. T, Kusche, C. A., \& Speltz, M. (1991). Emotional regulation, self control, and psychopathol ogy: The role of relationships in early childhood. In D. Cicchetti \& S. L. Toth (Eds.), Internalizing and exter nalizing expressions of dysfunction: Rochester symposium on developmental psychopathology (Vol. 2, pp. 21-66). Hillsdale, NJ: Erlbaum

Halpin, P.H., Wolf, S., Yoshikawa, H.Y., Rojas, N., Kabay, S., Pisani, L., \& Dowd, A.J. (2019). Measuring early learning and development across cultures: Invariance of the IDELA across five countries. Developmental Psychology, 55(1), 23-37.

Hanno, E. C., Jones, S. J., \& McCoy, D. C. (2019). The joint development of literacy and selfregulation in early childhood: Implications for research and practice. In Lesaux, N. (Ed.) The Handbook of Reading Research, Volume V. Routledge: New York. 
Hebert-Myers, H., Guttentag, C. L., Swank, P. R., Smith, K. E., \& Landry, S. H. (2006). The importance of language, social, and behavioral skills across early and later childhood as predictors of social competence with peers. Applied Developmental Science, 10(4), 174-187.

Henrich, J., Heine, S. J., \& Norenzayan, A. (2010). The weirdest people in the world?. Behavioral and Brain Sciences, 33(2-3), 61-83.

Hirsh-Pasek, K. (2009). A mandate for playful learning in preschool: Applying the scientific evidence. Oxford University Press.

Hu, L. T., \& Bentler, P. M. (1999). Cutoff criteria for fit indexes in covariance structure analysis: Conventional criteria versus new alternatives. Structural Equation Modeling: A Multidisciplinary Journal, 6(1), 1-55.

Izard, C., Fine, S., Schultz, D., Mostow, A., Ackerman, B., \& Youngstrom, E. (2001). Emotion knowledge as a predictor of social behavior and academic competence in children at risk. Psychological Science, 12(1), 18-23.

Jacob, R., \& Parkinson, J. (2015). The potential for school-based interventions that target executive function to improve academic achievement: A review. Review of Educational Research, 85(4), 512-552.

Jacob, R., \& Parkinson, J. (2015). The potential for school-based interventions that target executive function to improve academic achievement: A review. Review of Educational Research, $85(4), 512-552$.

Janus, M., \& Offord, D. R. (2007). Development and psychometric properties of the Early Development Instrument (EDI): A measure of children's school readiness. Canadian Journal of Behavioural Science, 39(1), 1. 
Jukes, M., Gabrieli, P., Mgonda, N. L., Nsolezi, F., Jeremiah, G., Tibenda, J., \& Bub, K. L. (2018). "Respect is an Investment": Community Perceptions of Social and Emotional Competencies in Early Childhood from Mtwara, Tanzania. Global Education Review, 5(2), 160-188.

Kline, R. B. (2015). Principles and practice of structural equation modeling: Fourth edition. New York, NY: Guilford Publications.

Ladd, G. W., Buhs, E. S., \& Seid, M. (2000). Children's initial sentiments about kindergarten: Is school liking an antecedent of early childhood classroom participation and achievement. Merrill-Palmer Quarterly, 46, 255-279.

Lamm, B., Keller, H., Teiser, J., Gudi, H., Yovsi, R. D., Freitag, C., ... \& Vöhringer, I. (2018). Waiting for the Second Treat: Developing Culture-Specific Modes of Self-Regulation. Child Development, 89(3), e261-e277.

Lan, X., Legare, C.H., Ponitz, C.C., Li, S., \& Morrison, F.J. (2011). Investigating the links between the subcomponents of executive function and academic achievement: a cross-cultural analysis of Chinese and American preschoolers. Journal of Experimental Child Psychology, 108(3), 677-692.

Leerkes, E. M., Paradise, M., O'Brien, M., Calkins, S. D. and Lange, G. 2008. Emotion and cognition processes in preschool children. Merrill-Palmer Quarterly, 54: 102-124.

Liew, J. (2012). Effortful control, executive functions, and education: Bringing self-regulatory and social-emotional competencies to the table. Child Development Perspectives, 6(2), 105-111.

Masten, A. S., \& Cicchetti, D. (2010). Developmental cascades. Development and psychopathology, $22(3), 491-495$.

Masten, A. S., Roisman, G. I., Long, J. D., Burt, K. B., Obradović, J., Riley, J. R., ... \& Tellegen, A. (2005). Developmental cascades: linking academic achievement and externalizing and internalizing symptoms over 20 years. Developmental psychology, 41(5), 733. 
Matthews, J. S., Ponitz, C. C., \& Morrison, F. J. (2009). Early gender differences in self-regulation and academic achievement. Journal of Educational Psychology, 101(3), 689.

McClelland, M. M., Cameron, C. E., Connor, C. M., Farris, C. L., Jewkes, A. M., \& Morrison, F. J. (2007). Links between behavioral regulation and preschoolers' literacy, vocabulary, and math skills. Developmental Psychology, 43(4), 947.

McClelland, M. M., Cameron, C. E., Duncan, R., Bowles, R. P., Acock, A. C., Miao, A., \& Pratt, M. E. (2014). Predictors of early growth in academic achievement: The head-toes-kneesshoulders task. Frontiers in Psychology, 5, 599.

McCoy, D. C., Peet, E. D., Ezzati, M., Danaei, G., Black, M. M., Sudfeld, C. R., ... \& Fink, G. (2016). Early childhood developmental status in low-and middle-income countries: National, regional, and global prevalence estimates using predictive modeling. PLoS Medicine, 14(1), e1002233.

McCoy, D. C., Salhi, C., Yoshikawa, H., Black, M., Britto, P., \& Fink, G. (2018). Home- and centerbased learning opportunities for preschoolers in low- and middle-income countries. Children and Youth Services Review, 88, 44-56.

McCoy, D. C., Zuilkowski, S. S., Yoshikawa, H., \& Fink, G. (2017). Early childhood care and education and school readiness in Zambia. Journal of Research on Educational Effectiveness, 10(3), 482-506.

McKown, C., Russo-Ponsaran, N. M., Allen, A., Johnson, J. K., \& Warren-Khot, H. K. (2016). Social-Emotional Factors and Academic Outcomes Among Elementary-Aged Children. Infant and Child Development, 25(2), 119-136.

Meixner, J. M., Warner, G. J., Lensing, N., Schiefele, U., \& Elsner, B. (2018). The relation between executive functions and reading comprehension in primary-school students: A cross-laggedpanel analysis. Early Childhood Research Quarterly. 
Miles, S. B., \& Stipek, D. (2006). Contemporaneous and longitudinal associations between social behavior and literacy achievement in a sample of low-income elementary school children. Child Development, 77(1), 103-117.

Miyake, A., Friedman, N. P., Emerson, M. J., Witzki, A. H., Howerter, A., \& Wager, T. D. (2000). The unity and diversity of executive functions and their contributions to complex "frontal lobe" tasks: A latent variable analysis. Cognitive Psychology, 41(1), 49-100.

Nix, R. L., Bierman, K. L., Domitrovich, C. E., \& Gill, S. (2013). Promoting children's socialemotional skills in preschool can enhance academic and behavioral functioning in kindergarten: Findings from Head Start REDI. Early Education \& Development, 24(7), 1000-1019. doi: 10.1080/10409289.2013.825565.

Nsamenang, A. B. (2007). A critical peek at early childhood care and education in Africa. Child Health and Education, 1(1), 14-26.

Nsamenang, A. B., \& Lamb, M. E. (1994). Socialization of Nso children in the Bamenda grassfields of Northwest Cameroon. Cross-cultural roots of minority child development, 133-146.

Osei, G. M. (2006). Teachers in Ghana: Issues of training, remuneration and effectiveness. International Journal of Educational Development, 26, 38-51.

Pace, A., Burchinal, P., Alper, R., Hirsh-Pasek, K., \& Golinkoff, R. M. (in press). Measuring success: Within and cross-domain predictors of academic and social trajectories in elementary school. Early Childhood Research Quarterly. [E-pub ahead of print].

Pisani, L., Borisova, I., \& Dowd, A.J. (2018). Developing and validating the International Development and Early Learning Assessment (IDELA). International Journal of Educational Research, 91, 1-15. 
Ponitz, C. C., McClelland, M. M., Matthews, J. S., \& Morrison, F. J. (2009). A structured observation of behavioral self-regulation and its contribution to kindergarten outcomes. Developmental psychology, 45(3), 605.

Rao, N., Sun, J., Ng, M., Becher, Y., Lee, D., Ip, P., \& Bacon-Shone, J. (2014). Validation, finalization and adoption of the East Asia-Pacific early child development scales (EAPECDS). New York: UNICEF.

Raver, C. (2003). Young children's emotional development and school readiness. Social Policy Report, 16(3), 3-19.

Raver, C. C., Jones, S. M., Li-Grining, C., Zhai, F., Bub, K., \& Pressler, E. (2011). CSRP's impact on low-income preschoolers' preacademic skills: self-regulation as a mediating mechanism. Child Development, 82(1), 362-378.

Razza, R. A., \& Blair, C. (2009). Associations among false-belief understanding, executive function, and social competence: A longitudinal analysis. Journal of Applied Developmental Psychology, 30(3), 332-343.

Rhoades, B. L., Warren, H. K., Domitrovich, C. E., \& Greenberg, M. T. (2011). Examining the link between preschool social-emotional competence and first grade academic achievement: The role of attention skills. Early Childhood Research Quarterly, 26(2), 182-191.

Riggs, N. R., Jahromi, L. B., Razza, R. P., Dillworth-Bart, J. E., \& Mueller, U. (2006). Executive function and the promotion of social-emotional competence. Journal of Applied Developmental Psychology, 27(4), 300-309.

Rimm-Kaufman, S. E., Curby, T. W., Grimm, K. J., Nathanson, L., \& Brock, L. L. (2009). The contribution of children's self-regulation and classroom quality to children's adaptive behaviors in the kindergarten classroom. Developmental Psychology, 45(4), 958.

RTI International (2016). Ghana 2015 Early Grade Reading Assessment and Early Grade 
Mathematics Assessment: Report of Findings. Retrieved from: https://iercpublicfiles.s3.amazonaws.com/public/resources/Ghana\%202015\%20EGRAEGMA_22Nov2016_FINAL.pdf.

Sandefur, J. (2016). Internationally Comparable Mathematics Scores for Fourteen African Countries (Working Paper No. 444). Washington, DC: Center for Global Development. http://dx.doi.org/10.2139/ssrn.2893768.

Schreiner, M., \& Woller, G. (2010). A simple poverty scorecard for Ghana. Consultative Group to Assist the Poorest.

Seidman, E., Kim, S., Raza, M., Ishihara, M., \& Halpin, P. F. (2018). Assessment of pedagogical practices and processes in low and middle income countries: Findings from secondary school classrooms in Uganda. Teaching and Teacher Education, 71, 283-296.

Serpell, R. (2011). Social Responsibility as a Dimension of Intelligence, and as an Educational Goal: Insights From Programmatic Research in an African Society. Child Development Perspectives, 5(2), 126-133.

Shonkoff, J. P. \& Phillips, D. A. (Eds.). (2000). From neurons to neighborhoods: The science of early childhood development. National Academies Press.

Slot, P.L., \& von Suchodoletz, A. (2018). Bidirectionality in preschool children's executive functions and language skills: Is one developing skill the better predictor of the other? Early Childhood Research Quarterly, 42, 205-214.

Squires, J., \& Bricker, D. (2009). Ages \& stages questionnaires, (ASQ-3). A parent-completed child monitoring system.

Taylor, R. D., Oberle, E., Durlak, J. A., \& Weissberg, R. P. (2017). Promoting positive youth development through school-based social and emotional learning interventions: A metaanalysis of follow-up effects. Child Development, 88(4), 1156-1171. 
UNESCO, G. (2015). Education for all 2000-2015: Achievements and challenges. EFA Global Monitoring Report, 500.

Ursache, A., Blair, C., \& Raver, C. C. (2012). The promotion of self-regulation as a means of enhancing school readiness and early achievement in children at risk for school failure. Child Development Perspectives, 6(2), 122-128.

Valiente, C., Eisenberg, N., Haugen, R. G., Spinrad, T. L., Hofer, C., Liew, J., \& Kupfer, A. (2011). Children's effortful control and academic achievement: Mediation through social functioning. Early Education \& Development, 22(3), 411-433.

von Suchodoletz, A., Uka, F., \& Larsen, R. A. (2015). Self-regulation across different contexts: Findings in young Albanian children. Early Education and Development, 26(5-6), 829-846.

Vygotsky, L. (1962). Language and Thought. Massachusetts Institute of Technology Press, Ontario. Weiland, C., \& Yoshikawa, H. (2013). Impacts of a prekindergarten program on children's mathematics, language, literacy, executive function, and emotional skills. Child Development, 84(6), 2112-2130.

Welsh, J. A., Nix, R. L., Blair, C., Bierman, K. L., \& Nelson, K. E. (2010). The development of cognitive skills and gains in academic school readiness for children from low-income families. Journal of Educational Psychology, 102(1), 43-53.

Willoughby, M. T., \& Blair, C. B. (2016). Measuring executive function in early childhood: A case for formative measurement. Psychological Assessment, 28(3), 319.

Winsler, A., Diaz, R. M., Atencio, D. J., McCarthy, E. M., \& Chabay, L. A. (2000). Verbal selfregulation over time in preschool children at risk for attention and behavior problems. Journal of Child Psychology and Psychiatry, 41(7), 875-886. 
Wolf, S., Aber, J.L., Behrman, J.R, \& Peele, M. (2019, in press). Longitudinal causal impacts of preschool teacher training on Ghanaian children's school-readiness: Evidence for persistence and fadeout. Developmental Science.

Wolf, S., Aber, J.L., Behrman, J.R., \& Tsinigo, E. (2018). Experimental impacts of the Quality Preschool for Ghana interventions on teacher professional well-being, classroom quality, and children's school readiness. Journal of Research on Educational Effectiveness. Advance online publication. https://doi.org/10.1080/19345747.2018.1517199

Wolf, S., Halpin, P., Yoshikawa, H., Pisani, L., Dowd, A., \& Borisova, I. (2017). Measuring school readiness globally: Assessing the construct validity and measurement invariance of the International Development and Early Learning Assessment (IDELA) in Ethiopia. Early Childhood Research Quarterly, 40(4), 21-36.

Wolf, S. \& Peele, M. (2019, in press). Examining sustained impacts of two teacher professional development programs on professional well-being and classroom practices. Teaching and Teacher Education.

Wolf, S., Raza, M., Kim, S., Aber, J.L, Behrman, J., \& Seidman, E. (2018). Measuring process quality in pre-primary classrooms in Ghana using the Teacher Instructional Practices and Processes System (TIPPS). Early Childhood Research Quarterly, 45, 18-30.

Zelazo, P. D., \& Carlson, S. M. (2012). Hot and cool executive function in childhood and adolescence: Development and plasticity. Child Development Perspectives, 6(4), 354-360.

Zhang, Y. (2006). Urban-rural literacy gaps in Sub-Saharan Africa: The roles of socioeconomic status and school quality. Comparative Education Review, 50(4), 581-602.

Zimmerman, B. J. (2000). Self-efficacy: An essential motive to learn. Contemporary educational psychology, 25(1), 82-91. 
Figure 1. Standardized coefficients from path analysis

\section{Time 1: Fall 2015}

Time 1: Fall 2015

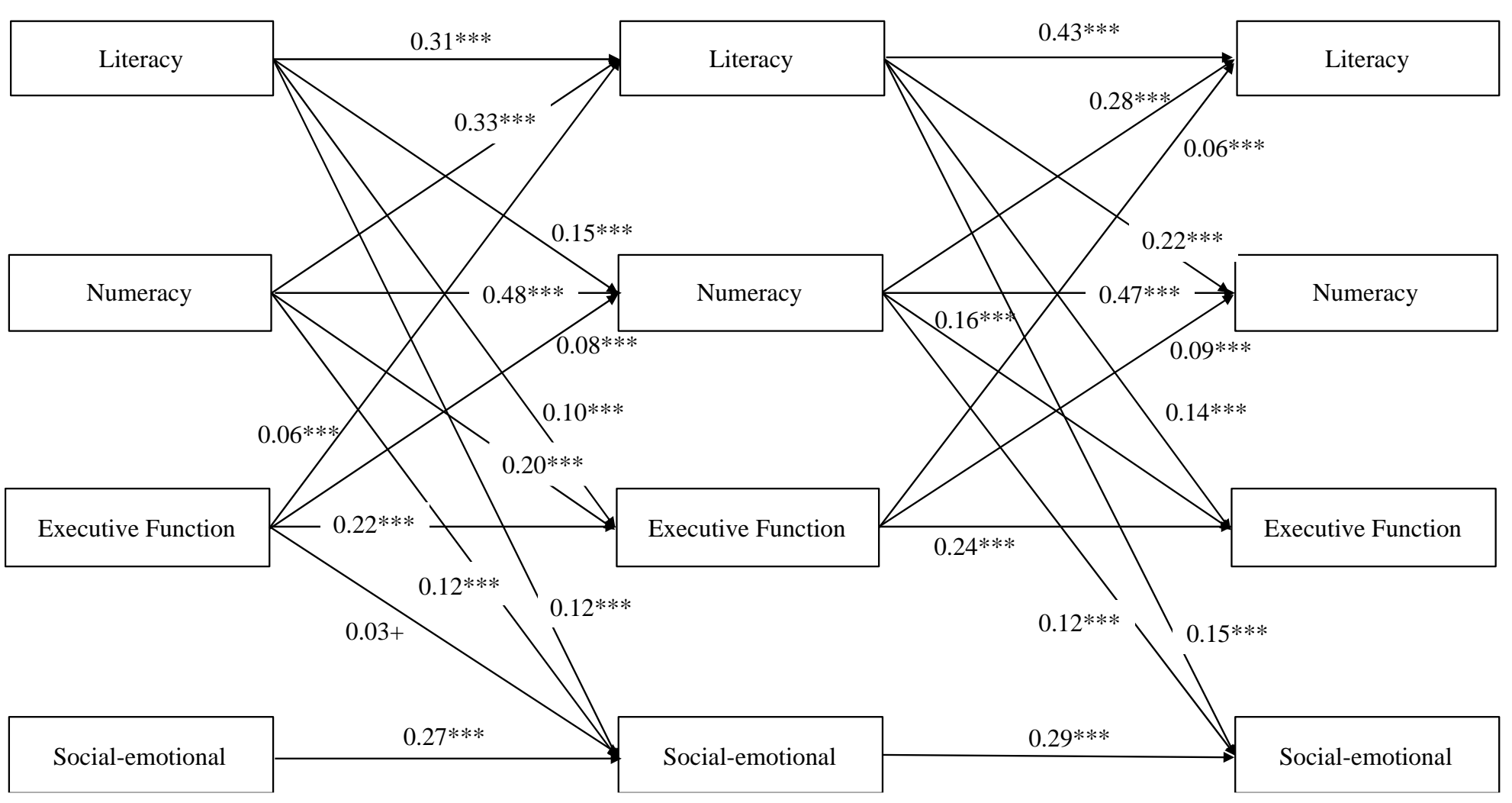

Notes. Models adjust S.E. estimates by school clusters. Error correlations between all domains within time points are included but not shown. Covariates predicting all endogenous variables include child age, child gender, household wealth at time 1, caregiver education level at time 1, number of books in the household at time 1, kindergarten grade level in the first academic year, treatment status indicators, a dummy indicator for whether the school in year 1 was private, and five dummy variables representing each districts in the region from which schools were sampled. Coefficients represent standardized estimates.

Model fit statistics: $\mathrm{RMSEA}=0.021, \mathrm{CFI}=0.976, \mathrm{TLI}=0.960, \mathrm{SRMR}=0.047$. 
Table 1. Sample characteristics

M or $\% \quad$ SD $\quad$ Range

\section{Child characteristics}

Child age (wave 1)

5.20

1.32

$3-11$

Child gender is male

$50.8 \%$

Grade level

KG1

$46.1 \%$

KG2

$42.9 \%$

Mixed KG class

$11.0 \%$

\section{Household characteristics}

Number of books in the home

Primary caregiver is female $50.90 \%$

Age of primary caregiver (years)

Caregiver's education level (\%)

$20.6 \%$

Less than primary school

Primary school

Junior high school

Secondary high school

O/A level, Vocational, or Diploma

Bachelor's degree or more

Household wealth (0-100) ${ }^{\mathrm{a}}$

Food Security (in the last 30 days)

No food due to lack of resources

Went to bed hungry

Spent a whole day and night without eating

\section{School characteristics}

Private (vs. public) school

$\underline{\text { School district }}$

Ga East

$7.2 \%$

$40.3 \%$

$13.2 \%$

$13.3 \%$

$5.0 \%$

60.81

$20.5 \%$

$11.3 \%$

$6.2 \%$

$53.4 \%$

Ga South

25.04

Adenta

12.94

Ledzokuku-Krower

22.25

Ga Central

13.12

Madina

11.17
3.69

$0-54$

8.9

$17-82$

-

$14-92$

$13.64 \quad 14-92$

${ }^{\text {a }}$ A score of 60 or below indicates a high likelihood of living in poverty. 
Table 2. Descriptive statistics and bivariate correlations of developmental skills at all time points

\begin{tabular}{|c|c|c|c|c|c|c|c|c|c|c|c|c|c|c|c|}
\hline & & $N$ & $M$ & $S D$ & 1 & 2 & 3 & 4 & 5 & 6 & 7 & 8 & 9 & 10 & 11 \\
\hline 1 & Early literacy T1 & 3,435 & 0.459 & 0.217 & & & & & & & & & & & \\
\hline 2 & Early numeracy T1 & 3,435 & 0.444 & 0.195 & 0.76 & & & & & & & & & & \\
\hline 3 & Executive function $\mathrm{T} 1$ & 3,435 & 0.488 & 0.207 & 0.50 & 0.48 & & & & & & & & & \\
\hline 4 & Social-emotional T1 & 3,435 & 0.414 & 0.199 & 0.55 & 0.52 & 0.43 & & & & & & & & \\
\hline 5 & Early literacy T2 & 3,402 & 0.614 & 0.201 & 0.70 & 0.68 & 0.44 & 0.40 & & & & & & & \\
\hline 6 & Early numeracy $\mathrm{T} 2$ & 3,402 & 0.575 & 0.189 & 0.65 & 0.73 & 0.47 & 0.42 & 0.74 & & & & & & \\
\hline 7 & Executive function T2 & 3,402 & 0.587 & 0.183 & 0.45 & 0.47 & 0.44 & 0.30 & 0.54 & 0.54 & & & & & \\
\hline 8 & Social-emotional T2 & 3,402 & 0.539 & 0.188 & 0.42 & 0.41 & 0.30 & 0.45 & 0.51 & 0.47 & 0.43 & & & & \\
\hline 9 & Early literacy T3 & 3,121 & 0.703 & 0.182 & 0.63 & 0.65 & 0.37 & 0.37 & 0.75 & 0.69 & 0.48 & 0.41 & & & \\
\hline 10 & Early numeracy T3 & 3,121 & 0.666 & 0.163 & 0.58 & 0.65 & 0.42 & 0.40 & 0.65 & 0.72 & 0.48 & 0.38 & 0.71 & & \\
\hline 11 & Executive function $\mathrm{T} 3$ & 3,121 & 0.636 & 0.161 & 0.41 & 0.42 & 0.42 & 0.26 & 0.48 & 0.47 & 0.47 & 0.28 & 0.52 & 0.49 & \\
\hline 12 & Social-emotional T3 & 3,121 & 0.583 & 0.169 & 0.40 & 0.38 & 0.32 & 0.44 & 0.41 & 0.40 & 0.29 & 0.46 & 0.46 & 0.40 & 0.30 \\
\hline
\end{tabular}

Notes. All skills scored as proportion correct from 0-1. 
Table 3. Cross-lagged effects of academic and non-academic skills

\begin{tabular}{|c|c|c|c|c|c|}
\hline & $b$ & S.E. & $p$-value & & $\beta$ \\
\hline \multicolumn{6}{|c|}{ Fall $2015(\mathrm{~T} 1) \rightarrow$ Spring $2016(\mathrm{~T} 2)$} \\
\hline \multicolumn{6}{|l|}{ Numeracy } \\
\hline Num T1 $\rightarrow$ Num T2 & 0.481 & 0.019 & 0.000 & $* * *$ & 0.499 \\
\hline Lit $\mathrm{T} 1 \rightarrow$ Num $\mathrm{T} 2$ & 0.152 & 0.019 & 0.000 & $* * *$ & 0.176 \\
\hline $\mathrm{EF} \mathrm{T} 1 \rightarrow$ Num $\mathrm{T} 2$ & 0.075 & 0.014 & 0.000 & $* * *$ & 0.083 \\
\hline $\mathrm{SE} \mathrm{T} 1 \rightarrow$ Num T2 & 0.006 & 0.015 & 0.677 & & 0.007 \\
\hline \multicolumn{6}{|l|}{ Literacy } \\
\hline Num $\mathrm{T} 1 \rightarrow$ Lit $\mathrm{T} 2$ & 0.331 & 0.019 & 0.000 & $* * *$ & 0.324 \\
\hline Lit T1 $\rightarrow$ Lit T2 & 0.314 & 0.019 & 0.000 & $* * *$ & 0.343 \\
\hline $\mathrm{EF} \mathrm{T} 1 \rightarrow$ Lit T2 & 0.063 & 0.016 & 0.000 & $* * *$ & 0.065 \\
\hline $\mathrm{SE} \mathrm{T} 1 \rightarrow$ Lit T2 & 0.007 & 0.015 & 0.651 & & 0.007 \\
\hline \multicolumn{6}{|l|}{ Executive function } \\
\hline Num T1 $\rightarrow$ EF T2 & 0.204 & 0.023 & 0.000 & $* * *$ & 0.218 \\
\hline Lit T1 $\rightarrow$ EF T2 & 0.098 & 0.021 & 0.000 & $* * *$ & 0.116 \\
\hline $\mathrm{EF} \mathrm{T} 1 \rightarrow \mathrm{EF}$ T2 & 0.222 & 0.018 & 0.000 & $* * *$ & 0.252 \\
\hline $\mathrm{SE} \mathrm{T} 1 \rightarrow \mathrm{EF}$ T2 & 0.002 & 0.018 & 0.896 & & 0.002 \\
\hline \multicolumn{6}{|l|}{ Social-emotional } \\
\hline Num T1 $\rightarrow$ SE T2 & 0.121 & 0.025 & 0.000 & $* * *$ & 0.125 \\
\hline Lit T1 $\rightarrow$ SE T2 & 0.122 & 0.024 & 0.000 & $* * *$ & 0.141 \\
\hline $\mathrm{EF} \mathrm{T} 1 \rightarrow \mathrm{SE} \mathrm{T} 2$ & 0.032 & 0.017 & 0.059 & + & 0.035 \\
\hline $\mathrm{SE} \mathrm{T} 1 \rightarrow \mathrm{SE} \mathrm{T} 2$ & 0.265 & 0.020 & 0.000 & $* * *$ & 0.280 \\
\hline \multicolumn{6}{|c|}{ Spring $2016(\mathrm{~T} 2) \rightarrow$ Spring 2017 (T3) } \\
\hline \multicolumn{6}{|l|}{ Numeracy } \\
\hline Num T2 $\rightarrow$ Num T3 & 0.407 & 0.018 & 0.000 & $* * *$ & 0.473 \\
\hline Lit T2 $\rightarrow$ Num T3 & 0.176 & 0.016 & 0.000 & $* * *$ & 0.216 \\
\hline $\mathrm{EF} \mathrm{T} 2 \rightarrow$ Num $\mathrm{T} 3$ & 0.083 & 0.014 & 0.000 & $* * *$ & 0.094 \\
\hline SE T2 $\rightarrow$ Num T3 & -0.002 & 0.013 & 0.853 & & -0.003 \\
\hline \multicolumn{6}{|l|}{ Literacy } \\
\hline Num T2 $\rightarrow$ Lit T3 & 0.270 & 0.018 & 0.000 & $* * *$ & 0.281 \\
\hline Lit T2 $\rightarrow$ Lit T3 & 0.391 & 0.017 & 0.000 & $* * *$ & 0.431 \\
\hline $\mathrm{EF} \mathrm{T} 2 \rightarrow$ Lit T3 & 0.063 & 0.015 & 0.000 & $* * *$ & 0.064 \\
\hline SE T2 $\rightarrow$ Lit T3 & 0.012 & 0.014 & 0.411 & & 0.012 \\
\hline \multicolumn{6}{|l|}{ Executive function } \\
\hline Num T2 $\rightarrow$ EF T3 & 0.164 & 0.022 & 0.000 & $* * *$ & 0.193 \\
\hline Lit T2 $\rightarrow$ EF T3 & 0.139 & 0.019 & 0.000 & $* * *$ & 0.174 \\
\hline $\mathrm{EF} \mathrm{T} 2 \rightarrow \mathrm{EF} \mathrm{T} 3$ & 0.238 & 0.020 & 0.000 & $* * *$ & 0.272 \\
\hline
\end{tabular}




\begin{tabular}{llllll} 
SE T2 $\rightarrow$ EF T3 & 0.002 & 0.016 & 0.913 & & 0.002 \\
Social-emotional & & & & & \\
Num T2 $\rightarrow$ SE T3 & 0.106 & 0.023 & 0.000 & $* * *$ & 0.119 \\
Lit T2 $\rightarrow$ SE T3 & 0.123 & 0.021 & 0.000 & $* * *$ & 0.145 \\
EF T2 $\rightarrow$ SE T3 & 0.027 & 0.017 & 0.117 & & 0.029 \\
SE T2 $\rightarrow$ SE T3 & 0.286 & 0.017 & 0.000 & $* * *$ & 0.319 \\
\hline
\end{tabular}

Notes. Sample size $=3,862$ children. Models adjust S.E. estimates by school clusters. Error correlations between all domains within time points are included but displayed. Covariates predicting all endogenous variables include child age, child gender, household wealth at time 1, caregiver education level at time 1 , number of books in the household at time 1, kindergarten grade level in the first academic year, treatment status indicators, a dummy indicator for whether the school in year 1 was private, and five dummy variables representing each districts in the region from which schools were sampled. 
Table 4. Cross-lagged effects of academic and non-academic skills by kindergarten grade level

\begin{tabular}{cccc}
\hline & KG1 & & KG2 \\
\hline$b$ & S.E. & $b$ & S.E. \\
\hline
\end{tabular}

Fall 2015 (T1) --> Spring 2016 (T2)

Numeracy $T 2$

Num T1 $\rightarrow$ Num T2

Lit $\mathrm{T} 1 \rightarrow \mathrm{Num} \mathrm{T} 2$

$\begin{array}{lll}0.461 & 0.032 & * * * \\ 0.197 & 0.028 & * * * \\ 0.083 & 0.020 & * * * \\ 0.001 & 0.024 & \end{array}$

0.494

$0.029 * * *$

$\mathrm{EF}$ T1 $\rightarrow$ Num T2

$\mathrm{SE} \mathrm{T} 1 \rightarrow \mathrm{Num} \mathrm{T} 2$

Literacy T2

Num T1 $\rightarrow$ Lit T2

Lit T1 $\rightarrow$ Lit T2

EF T1 $\rightarrow$ Lit T2

$\mathrm{SE} \mathrm{T} 1 \rightarrow$ Lit T2

Executive function $T 2$

Num T1 $\rightarrow$ EF T2

Lit T1 $\rightarrow$ EF T2

$\mathrm{EF}$ T1 $\rightarrow$ EF T2

$\mathrm{SE} \mathrm{T} 1 \rightarrow \mathrm{EF}$ T2

Social-emotional T2

Num T1 $\rightarrow$ SE T2

0.306

0.030

0.333

$0.038 * * *$

0.050

0.022

0.021

0.023

0.098

$0.027 * * *$

Lit $\mathrm{T} 1 \rightarrow \mathrm{SE}$ T2

0.238

0.034

0.110

0.033

0.219

0.038

0.064

$0.019 * *$

$\mathrm{EF}$ T1 $\rightarrow$ SE T2

0.032

0.036

0.001

0.020

$\mathrm{SE} \mathrm{T} 1 \rightarrow \mathrm{SE}$ T2

$\begin{array}{lll}0.091 & 0.038 & * \\ 0.157 & 0.031 & * * * \\ 0.022 & 0.027 & \\ 0.298 & 0.028 & * * *\end{array}$

0.331

0.029

0.290

0.029

0.073

0.021

$-0.017$

0.021

0.191

$0.032 * * *$

0.059

0.217

$0.020+$

$-0.034 \quad 0.024$

Spring 2016 (T2) --> Spring 2017 (T3)

Numeracy T3

$$
\begin{aligned}
& \text { Num T2 } \rightarrow \text { Num T3 } \\
& \text { Lit T2 } \rightarrow \text { Num T3 } \\
& \text { EF T2 } \rightarrow \text { Num T3 } \\
& \text { SE T2 } \rightarrow \text { Num T3 }
\end{aligned}
$$

Literacy $\mathrm{T} 3$

Num T2 $\rightarrow$ Lit T3

Lit T2 $\rightarrow$ Lit T3

$\mathrm{EF} \mathrm{T} 2 \rightarrow$ Lit T3

$\mathrm{SE} \mathrm{T} 2 \rightarrow$ Lit T3

Executive function $T 3$

Num T2 $\rightarrow$ EF T3

Lit T2 $\rightarrow$ EF T3

$\begin{array}{llllll}0.437 & 0.025 & * * * & 0.380 & 0.029 & * * * \\ 0.145 & 0.024 & * * * & 0.178 & 0.023 & * * * \\ 0.095 & 0.019 & * * * & 0.065 & 0.022 & * * \\ -0.012 & 0.018 & & 0.022 & 0.019 & \\ & & & & & \\ 0.326 & 0.027 & * * * & 0.200 & 0.027 & * * * \\ 0.354 & 0.028 & * * * & 0.393 & 0.024 & * * * \\ 0.048 & 0.022 & * & 0.072 & 0.020 & * * * \\ 0.019 & 0.021 & & 0.012 & 0.020 & \end{array}$

$\begin{array}{llllll}0.195 & 0.031 & * * * & 0.148 & 0.030 & * * * \\ 0.104 & 0.033 & * * & 0.132 & 0.028 & * * *\end{array}$


$\mathrm{EF} \mathrm{T} 2 \rightarrow \mathrm{EF} \mathrm{T} 3$

$0.230 \quad 0.028 * * *$

0.248

0.028

$\begin{array}{ll}-0.032 & 0.022\end{array}$

$\mathrm{SE} \mathrm{T} 2 \rightarrow \mathrm{EF}$ T3

0.026

0.024

0.136

$0.037 * * *$

0.088

$0.033 * *$

Num T2 $\rightarrow$ SE T3

$0.110 \quad 0.034 * *$

0.099

0.029

$0.035 \quad 0.028$

$\mathrm{EF} \mathrm{T} 2 \rightarrow \mathrm{SE} \mathrm{T} 3$

0.020

0.024

0.306

$0.025 * * *$

Sample size

0.252

1658

Notes. Sample size $=3,437$ children and excludes children who were in a mixed grade class. Models adjust S.E. estimates by school clusters. Error correlations between all domains within time points are included but displayed. Covariates predicting all endogenous variables include child age, child gender, household wealth at time 1, caregiver education level at time 1, number of books in the household at time 1 , treatment status indicators, a dummy indicator for whether the school in year 1 was private, and five dummy variables representing each districts in the region from which schools were sampled Coefficients represent standardized estimates. 
Appendix Figure 1. Kernel density plots of each developmental domain at each time point
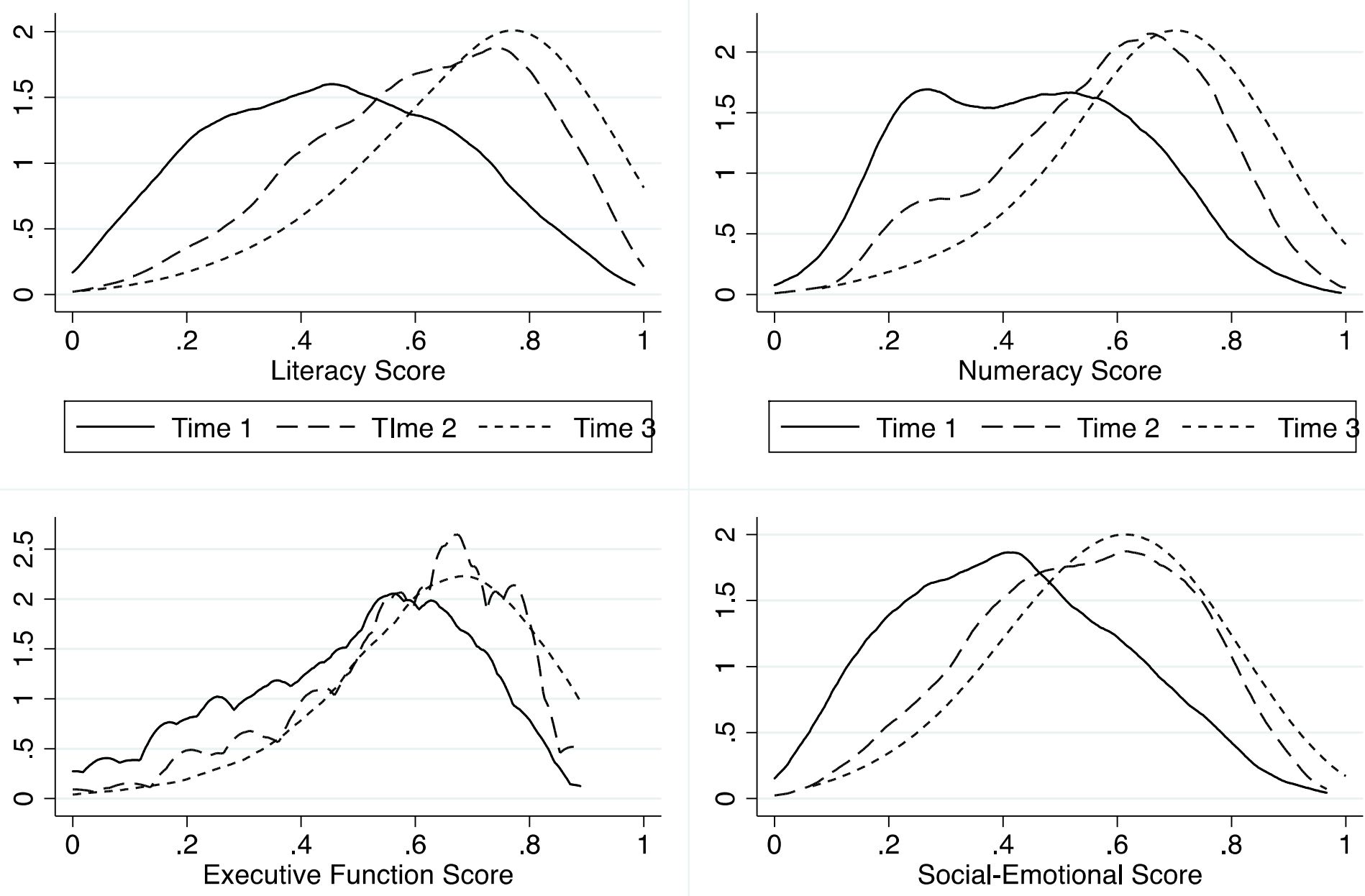

Time 1 - - - Time 2 ---- Time 3

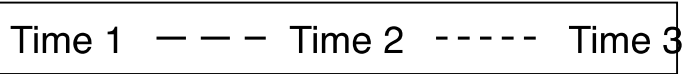


Appendix Table 1. Sensitivity analyses examining cross-lagged effects of academic and non-academic skills

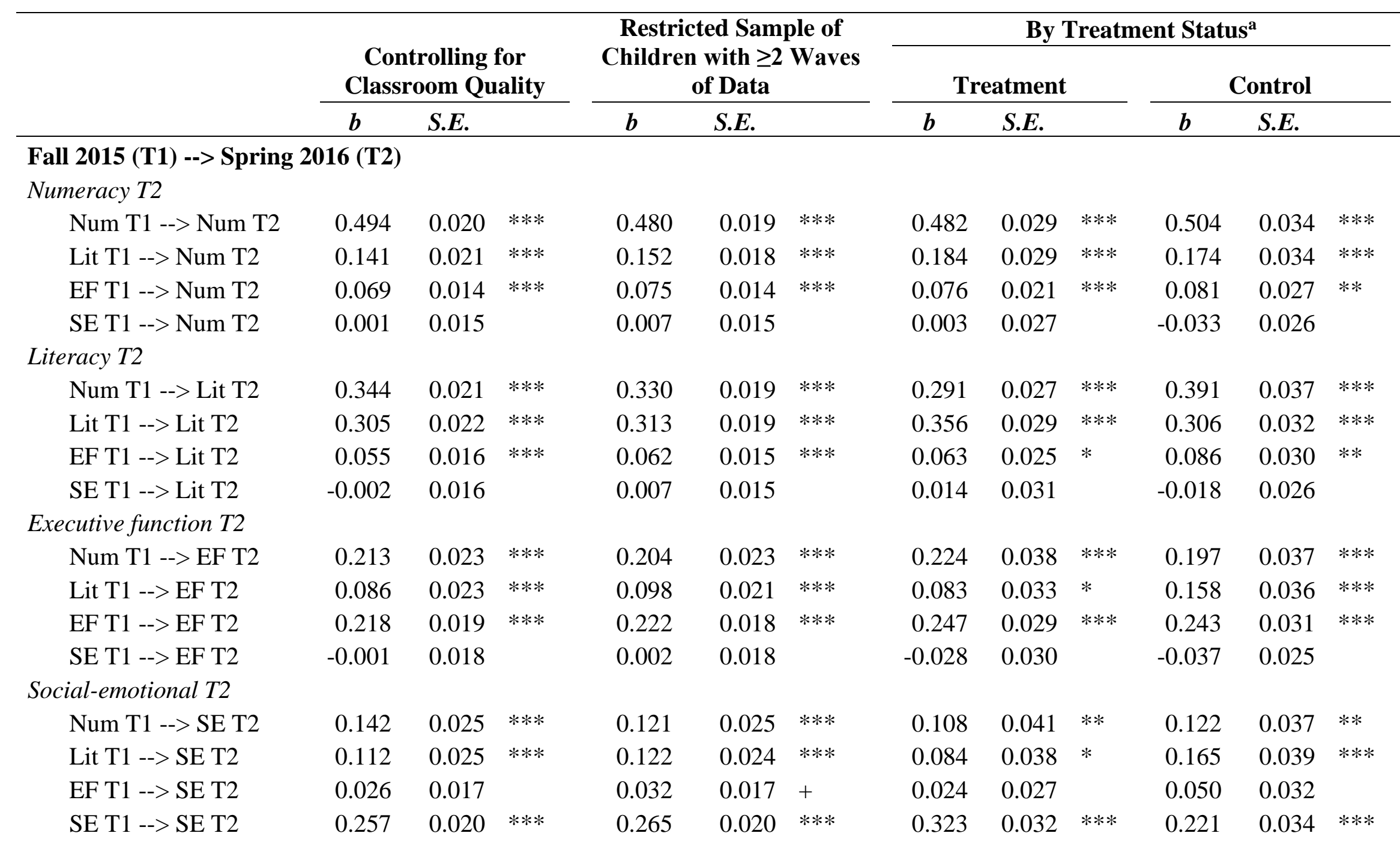


Spring 2016 (T2) --> Spring 2017 (T3)

Numeracy T3

\begin{tabular}{lccccccccccccc} 
Num T2 --> Num T3 & 0.412 & 0.018 & $* * *$ & 0.406 & 0.018 & $* * *$ & 0.423 & 0.032 & $* * *$ & 0.388 & 0.033 & $* * *$ \\
Lit T2 --> Num T3 & 0.179 & 0.016 & $* * *$ & 0.175 & 0.016 & $* * *$ & 0.186 & 0.031 & $* * *$ & 0.158 & 0.029 & $* * *$ \\
EF T2 --> Num T3 & 0.083 & 0.014 & $* * *$ & 0.083 & 0.014 & $* * *$ & 0.068 & 0.024 & $* *$ & 0.076 & 0.024 & $* *$ \\
SE T2 --> Num T3 & -0.002 & 0.013 & & -0.002 & 0.013 & & 0.006 & 0.022 & & 0.014 & 0.025 \\
iteracy T3 & & & & & & & & & & & \\
Num T2 --> Lit T3 & 0.274 & 0.018 & $* * *$ & 0.269 & 0.018 & $* * *$ & 0.293 & 0.027 & $* * *$ & 0.292 & 0.036 & $* * *$ \\
Lit T2 --> Lit T3 & 0.394 & 0.017 & $* * *$ & 0.391 & 0.017 & $* * *$ & 0.396 & 0.030 & $* * *$ & 0.388 & 0.032 & $* * *$ \\
EF T2 --> Lit T3 & 0.063 & 0.015 & $* * *$ & 0.063 & 0.015 & $* * *$ & 0.058 & 0.025 & $*$ & 0.041 & 0.030 \\
SE T2 --> Lit T3 & 0.013 & 0.014 & & 0.012 & 0.014 & & 0.016 & 0.025 & & 0.017 & 0.026 \\
xecutive function T3 & & & & & & & & & & & \\
Num T2 --> EF T3 & 0.165 & 0.021 & $* * *$ & 0.164 & 0.022 & $* * *$ & 0.169 & 0.043 & $* * *$ & 0.162 & 0.035 & $* * *$ \\
Lit T2 --> EF T3 & 0.140 & 0.019 & $* * *$ & 0.139 & 0.019 & $* * *$ & 0.174 & 0.033 & $* * *$ & 0.106 & 0.034 & $* *$ \\
EF T2 --> EF T3 & 0.238 & 0.020 & $* * *$ & 0.238 & 0.020 & $* * *$ & 0.248 & 0.034 & $* * *$ & 0.255 & 0.032 & $* * *$ \\
SE T2 --> EF T3 & 0.002 & 0.016 & & 0.002 & 0.016 & & -0.027 & 0.025 & & 0.007 & 0.030 \\
Sial-emotional T3 & & & & & & & & & & & \\
Num T2 --> SE T3 & 0.110 & 0.023 & $* * *$ & 0.106 & 0.023 & $* * *$ & 0.035 & 0.043 & & 0.123 & 0.041 & $* *$ \\
Lit T2 --> SE T3 & 0.126 & 0.021 & $* * *$ & 0.122 & 0.021 & $* * *$ & 0.186 & 0.034 & $* * *$ & 0.103 & 0.037 & $* *$ \\
EF T2 --> SE T3 & 0.027 & 0.017 & & 0.027 & 0.017 & & 0.043 & 0.032 & & 0.022 & 0.025 \\
SE T2 --> SE T3 & 0.286 & 0.017 & $* * *$ & 0.286 & 0.017 & $* * *$ & 0.262 & 0.030 & $* * *$ & 0.301 & 0.030 & $* * *$ \\
\hline ample size & & 3,862 & & & 3,439 & & 2,645 & & 1,217 &
\end{tabular}

Notes. $* * * p<.001 ; * * p<.01 ; * p<.05,+p<.10$.

${ }^{a}$ Treatment status includes children combined from both treatment arms. The chi square difference test compared to the main model presented in Table 3 was non-significant $\left(\chi^{2}\right.$ diff $\left.(113)=67.52, p=0.999\right)$, indicating that the model in which parameters were allowed to vary across the treatment and control groups did not fit the data better than the primary model. 